\title{
The Implementation of a Computerised
}

\section{Integrated System in a Public Service Organisation}

\author{
Julie Griffin \\ Finance Department, Cork County Council, Cork, Ireland \\ Tel: 353-21-432-6674Ｅ-mail: Julie.griffin@Corkcoco.ie \\ Sylvia Dempsey (Corresponding author) \\ School of Business, Cork Institute of Technology, Cork, Ireland \\ Tel: 353-21-4326-674 E-mail: sylvia.dempsey@cit.ie
}

\begin{abstract}
To survive in a customer focused environment, organisations have had to become more effective and efficient. The promised benefits of integrated systems made their implementation a popular attempt at such success in the private sector. The implementation of integrated systems in the private sector is well documented. However, integrated systems are still a relatively new phenomenon in the public sector. One of the researchers of this paper was working as an accountant, in Cork County Council in Ireland, when it deciding to, and then tendering for, a new computerised integrated system. Recognising the gap in the literature in this regard, and having the opportunity to act as participant observers, the researchers decided this would be a worthy area of research. This study is a descriptive case study examining the decision to implement, and the tendering process for, an integrated system in Cork County Council.
\end{abstract}

Keywords: Integrated System, Centralisation, Debtor Management, Needs Assessment

\section{Introduction}

Cork County Council is a local government authority in Ireland. It has three divisions: North Cork, South Cork and West Cork. It is responsible for providing services such as water, refuse, housing and roads to the people of County Cork. It is managed by the County Manager, who is supported by the heads of the various departments. Each of the divisions was responsible for its own billing and receipting. This resulted in diverse billing and receipting procedures. The Head of Finance and the County Manager suggested setting-up of centralised Debtors unit with an integrated Corporate Debtors System. While the centralised debtors unit could deal with the billing, receipting and customer account enquiries, each of the divisions could then focus on service delivery.

In the period from November 2005 to September 2006 the Council decided the type of system it required and tendered for such a system. By May 2007 a new centralised integrated Corporate Debtors System was successfully implemented. The first service to be rolled out on the new Corporate Debtors System was Water, the integrated system will later assume responsibility for other income streams such as Rates, Refuse, Rents, Annuities, Roads and Development Contributions.

One of the researchers was employed by Cork County Council, as an accountant, when the decision was made to implement a new integrated system for the new debtors unit. She was involved in the project throughout the processes of tendering, implementation and training. Having recognised that the implementation of an integrated system in a local government authority was such a major gap in the literature, the researchers decided this would be a worthy area of participatory research.

This paper will first take a look at the literature available on integrated systems and compare and contrast single-vender enterprise resource planning (EPP) systems and Best-of-Breed (BoB) systems. It will also look at the limited literature on integrated systems in the public sector. The next section describes the research methodology chosen. The third section describes the decision to implement an integrated system in Cork County Council and the tendering process for such a system. Finally in the conclusion further areas of research are suggested.

\section{Literature Review}

Integrated information systems are defined as "the extent to which different operational functions are tied together in the overall system" (Miranda 1999, p11). Integration can be achieved by developing system interfaces which links the software of the separated functions of the organisation (Moriarty, 1999; Chester, 2006). The ultimate in 
integrated systems is the single vendor Enterprise Resource Planning (ERP) system. ERP systems are standard consolidated software packages that comprise many, if not all, of the functions of the entire organisation. It is because of this integration of the different business processes of the organisation that ERP systems can provide up-to-date, real-time information to their users (Davenport, 1998; Miranda, 1999; Scapens and Jazayeri, 2003; Newman and Westrup, 2005). The term ERP is therefore a misnomer. ERP systems do connect the divisions of an enterprise and certainly do focus on resources, however they go way beyond planning, they also facilitate financial and operational decision-making and refine reporting (Davenport, 1998, Miranda, 1999; Klaus et al, 2000; Botta-Genoulaz and Millet, 2006; Rikhardsson and Kraemmergaard, 2006). In fact, Davenport (1998) and Rikhardsson and Kraemmergaard (2006) refer to integrated systems as ES (Enterprise Systems) rather than ERP systems (Enterprise Resource Planning).

Replacing all of the existing, separate legacy systems and databases within the business with an ERP system, is not the only way to solve integration problems (Moriarty, 1999; Hyvonen, 2003; Global Supply Chain Conference, 2006; Chester, 2006), a best-of-breed (BoB) strategy can also be implemented. A BoB strategy involves interfacing the 'best' available softwares for each function and therefore they do not automatically share a common database (Miranda, 1999; Moriarty, 1999; Hyvonen, 2003). The functionality required from the system, the ability of your own IT department, the resulting relationship with the vendors and of course the cost, are the major issues you have to examine when deciding between an ERP system and a BoB system. An organisation's integrated systems strategy should be based on its own unique business environment (Griffith, 2000).

\subsection{ERP versus $B o B$}

What if the functionality offered by an ERP system does not fulfil the requirements of your organisation? The options open to you are to either customise the ERP system or look for a BoB package (Hyvonen, 2003; Millman, 2004). Customisation is often frowned upon (Holland and Light, 1999; Nah et al, 2003; Nah and Delgado, 2006) this can be an expensive process and therefore if a company takes this route it is stuck with it. Whereas a BoB package can be amended, deleted or enhanced when and if required. BoBs tend to focus on a particular business requirement which usually results in greater functionality (Moriarty, 1999; Griffith, 2000; Chester; 2006). However Langnau (2004) writes that while ERP systems may not focus on the particular business requirements "that loss is now viewed as better than trying to tie multiple disparate systems together" (p48).

Therefore another issue is to determine the complexity of the interfacing required by your organisation. If the interfacing is very complex then ERP systems may take the lead (Geishecker, 1999) as they are promoted for reducing interfaces as the package covers most corporate business applications (Griffith, 2000). However BoBs are a viable option if the "anticipated interfaces consist of passing information back and forth with little or no translation and programming required" (Geishecker 1999, p66). Therefore, in making the decision as to whether to adopt an integrated system or a BoB system, you need to look at the complexity of the interfaces and the corresponding skills and facilities of your own IT department for working with these interfaces (Griffith, 2000; Chester, 2006).

Another important question to ask is do you want to lock yourself into a relationship with a single vendor ERP supplier? If so you have to be aware of the viability and financial status of their potential vendors. Some companies have implemented BoB systems to avoid being tied into one supplier (Botta-Genoulas and Millet, 2006). However, this route results in the maintenance of a greater number of vendor management and sales relationships (Chester, 2006). This may impact on the speed at which technical issues are resolved as vendors cannot be expected to be experts on another firm's products (Chester, 2006).

It is very difficult to compare the cost of an ERP system and a BoB system if they are delivering different functionality. It is important, that you are costing and buying only the features that you need (Chester, 2006). There is a lot of evidence in the literature examined of ERP implementation processes going way over budget. Integration costs such as integrating your new product to your legacy systems and integrating the pieces of BoB set to each other can also be very expensive (Geishecker, 1999; Chester, 2006). Often, training costs for a BoB can be more expensive than for an ERP system (Chester, 2006) due to the intricacies of the individual pieces of software. These life-cycle costs are difficult to estimate but must be included in the comparison of ERP and BoB costs.

Integrated systems adoption is a complex exercise involving not only technology but also fundamental organisational change (Markus and Tanis, 2000; Kumar et al, 2002). In the literature, these systems were initially viewed as a computer topic when in fact it is "very much a people related business subject" (Botta-Genoulas and Millet 2006, p205). Research has revealed that if companies adopt the attitude that "once data is integrated, people will follow" the result can be a failed integrated systems implementation (Botta-Genoulaz and Millet 2006, p218).

\subsection{Public Sector}

In public sector organisations adoption of new information technology (IT) innovations are affected by government 150 
influence, and political and legal factors (Miranda, 2002; Kumar et al, 2002; Lapsley and Wright, 2004; Ramon Gil-Garcia and Pardo, 2005; Botta-Genoulaz and Millet, 2006). Public sector organisations want to be viewed as service providers that meet the needs of their customers (Miranda, 1999; Lapsley and Pallot, 2000, Ramon Gil-Garcia and Pardo, 2005). Integrated systems promise better quality of service to customers. But as well as improved customer service, the improved functionality of integrated systems also helps to eliminate multiple data entries that were present in stand alone legacy systems, improve working procedures and aid in cost reductions (Miranda, 1999; Kumar et al, 2002; Miranda, 2003; Lapsley and Wright, 2004; Miranda and Kavanagh, 2005; Ramon Gil-Garcia and Pardo, 2005; Botta-Genoulaz and Millet, 2006).

Governments cannot be seen to be spending public money on failed systems implementations (Miranda, 2002). The Irish government spent millions on a PPARS health payroll and personnel system only to have it halted due to systems errors and huge escalating costs (Hunter, 2005). An external examination of the PPARS system claimed that part of the reason for the failed systems implementation was due to not properly defining the business needs of the health sector organisation prior to the system going live (Hunter, 2005).

In order to prevent failed systems implementation the existing legacy systems must be reviewed by looking at their major deficiencies, deciding whether the technology is obsolete, asking is there poor management and poor staff training (Miranda, 2002). Alternatives should then be identified, researched and documented. For public sector organisations, the procurement of an integrated system is not only a huge capital investment, but also a highly political process. In Europe, local authorities must invite tenders for purchases greater than $€ 50,000$. The tender document must display details of the organisations requirements and terms of the contract.

The local authority then needs to select a supplier based on the selection criteria (Botta-Genoulaz and Millet, 2006). Once the procurement team selects two vendors from the applications submitted, each vendor should be invited to the government site to meet with the team and have a 'discovery' discussion which allows the "vendors to ask questions and find answers (e.g., number and type of interfaces required and data file dimensions)" (Madden and Miranda 1998, p37). The purpose of this session is to allow the vendors the opportunity to refine the scope/cost of their proposals (Madden and Miranda, 1998). Upon selection of the single vendor the government team must then finalise the terms and conditions of the contract. It is clear that the contract must not be seen as a strait-jacket. It must be sufficiently adaptable to deal with the modern, ever-changing environment of the public sector organisation.

\section{Research Methodology}

As a result of reviewing the literature available, the researcher recognised a gap which has not yet been adequately covered. Much has been written on successful integrated systems implementation in the private sector, but very little had been written about such an implementation in the public sector. The objective of this paper is to examine, in a Local Authority environment, the decision to implement, and the tendering for, an integrated system.

\subsection{Research method}

The researchers chose the qualitative single case-study method of research. By concentrating on one Local Authority, an in-depth view of the organisation is provided. Cork County Council was chosen for two reasons. First it represents an excellent example of a typical public sector organisation implementing an integrated system. Second as one of the researchers was employed by Cork County Council it was a unique opportunity for her in relation to access to information and of course access to time. The issue of bias by the researcher had to be examined. This was overcome in two ways. The second researcher was an employee of Cork County Council and thus viewed the research as an external agent and triangulation by use of multiple methods for data collection was used throughout to confirm the findings.

\subsection{Research tools}

The researchers used both structured and unstructured interviews. The unstructured interviews involved meetings with various people on the project throughout the organisation. The researchers then conducted structured interviews with those directly involved in the project. These interviewees were sent a copy of the proposed interview questions shortly before the interview. Throughout the interviews open-ended questions were used, allowing the interviewees to expand beyond the issues already identified and explore new issues in greater detail.

In this study, one of the researchers, due to her role as a participant observer, had access to internal documents. The documentation types used were tender documents, emails, minutes of meetings, proposals, progress reports, presentations, CD-Roms, and training manuals. These provided confirmation of information obtained from the interviews and they provided more rounded information. The researcher in this study acknowledges the fact that the documents were prepared for a specific purpose rather than for the case study. By bearing this in mind during the 
analysis of the case study the researchers were not mislead by the contents of the documents.

\section{Decision to Implementing and Tendering Process}

Prior to the centralisation of Cork County Council's debtors, it used to operate the Water Debtors Legacy application that was written in-house for each division by Cork County Council's IT staff. This Water Debtors Legacy System was the system which held all the information relating to the customers, such as the billing address and customers' water location address. It also held the invoice charge, receipts figure, refunds and any amendments made to the customers' accounts.

Cork County Council used JD Edwards (JDE) World to produce the Annual Financial Statements. Despite JDE being an ERP system, Cork County Council did not transfer its major services such as Water, Rates, Rents, Annuities and Roads from their respective legacy systems to the JDE AR module due to limited JDE AR functionality. The legacy systems had much more appropriate functionality and movement to JDE AR would have been seen as a backward step.

"The financial information that the AR module provided was too limited in its structure and it was agreed by both the finance department and IT department that a move to the JDE AR module would not be a good management decision". (Note 1)

"Much work was done in investigating whether the JDE AR module could be used to incorporate all of the Councils debtors legacy systems, however it was decided it could not, therefore all the legacy systems were retained until a better solution was found". (Note 2)

Therefore, for these services the General Ledger (GL) module of JDE remained independent of the main Debtors Legacy applications.

As well as the complexity of the billing and receipting processes in multiple division, new pricing policy issues were introduced, pushing Cork County Council towards implementing a new integrated Corporate Debtors System.

\subsection{Define the problem}

A needs assessment was initiated by the Finance Department in November 2005. It revealed that the existing Water Debtors Legacy Systems were becoming dated and no longer provided enough information such as Debtors Aged Analysis for management purposes. However it did confirm that existing Water Debtors Legacy System had more functionality than JDE could offer. So even though the Water Debtors Legacy Systems had more functionality than JDE, they still could have been improved upon.

The Finance Department expressed a need to have all three divisions of Cork County Council operating in a similar fashion. The three divisions should bill customers in a similar way, amend customers' accounts in a standardised fashion and collect monies from debtors in an equitable manner. These issues drove the need for a solution that would implement consistent and accurate methods for the billing and receipting of water services within Cork County Council.

\subsection{Identify and Research alternatives}

After examining the existing Legacy Systems, Cork County Council had a clearer vision of what it required from a new system. The next step was to identify and evaluate possible options. Four options were identified and evaluated:

The first possible option identified was to outsource the billing and receipting of Water to an external contractor. This was rejected at tender stage as the cost was so high it was rendered prohibitive. Also Cork County Council was anxious to modernise its debtors systems for all streams of income, and by doing it in-house for one stream of income, would make it easier to later include the other streams.

The next option was to transfer the Water Debtors Legacy Systems over to the Accounts Receivable (AR) module of JDE. The main advantage of this option would be that it would eliminate the need for creating interfaces as JDE is a fully integrated Enterprise Resource Planning (ERP) system. After discussion and tests carried out on the JDE AR module, it was confirmed that the functionality offered by the existing Debtors Legacy Systems could not be provided by the existing or even upgraded JDE AR module in Cork County Council. The Senior Executive Officer (SEO) of ICT said:

"The functionality of JDE AR was not sufficient or robust enough to support an Irish Local Authority without considerable and costly modifications". (Note 3)

The Head of Finance supported this view stating;

"It is suffice to say that generally AR modules in ERP systems are developed for production companies and don't necessarily sit well for Service companies". (Note 4) 
This option although initially preferred by the Finance Department was rejected for these reasons. There would have been huge costs involved in upgrading the JDE AR module to provide the billing and receipting functionality required by Cork County Council.

The third option identified was to continue with the existing Debtors Legacy Systems and interface them into the JDE GL. These Debtors Legacy Systems would need to be upgraded for new water pricing rules and other new issues in financial accounting in the public sector. Interfaces would also have to be built into the JDE GL. According to the SEO (ICT):

"it was thought that the investment that would have been needed to achieve this would be wasted, and not inline with Cork County Councils long term plan to have all income streams operating off the same system".

\section{(Note 5)}

This option was rejected because the investment may not have been worth it and other options had better functionality.

The fourth option, and the option which was decided upon, was to implement a centralised billing and receipting system known as the Corporate Debtors System. This would replace the numerous existing legacy systems and would be interfaced into the JDE Financial Management System. This would also be seen to support a modernisation agenda for Cork County Council.

The main reason why Cork County Council opted to interface the Corporate Debtors System into JDE, as opposed to purchasing a new ERP system was because it wanted to retain its existing JDE asset management, procurement and general ledger modules. Both ICT and the Finance personnel were in agreement on this.

"We did not go to tender for a new ERP system. We already had one in the case of JDE" (Note 6)

"The JDE GL suite at present is satisfying all other financial requirements" (Note 7)

Once the needs assessment was completed and the best possible option (that is Option D) was agreed, the next step was the tendering process. As stated earlier, EU law states that local authorities must invite tenders for purchases greater than $€ 50,000$.

\subsection{Tender Documents}

Due to the complexity of the system required, the Cork County Council decided on a restricted rather than an opentender competition which is in accordance with EU procurement procedures. In a restricted competition, vendors must submit answers to a pre-qualification questionnaire. The applicants had thirty days to reply to the questionnaire. This questionnaire focuses on the three areas of vendors' economic standing, staff resources and track record with similar projects. As stated by the SEO of Finance:

"The questionnaire allowed Cork County Council to gain an understanding of the bidder's financial standing, its capability for the project, how many employees it has, what type of back-up and support it can provide and what type of work it has carried out before" (Note 8)

Therefore only vendors with a realistic chance of winning the contract make it through the pre-qualification stage. This resulted in a much smaller, and therefore manageable, number of tender documents being submitted. Cork County Council received four replies to the pre-qualification questionnaire within the time period. The SEO (Finance) and the SEO (ICT) assessed the pre-qualification questionnaires to reveal that two of the four vendors did not meet the pre-qualification standards and were eliminated from the tender competition. The two remaining vendors met the standards required at this stage and the formal full tender documents were forwarded to both of them on 3 April 2006. They were given forty days to respond. Both vendors in the competition submitted tenders and these were opened at the Council meeting on 22 May 2006.

\subsection{Assessment of Tenders}

Once the procurement team selects two vendors from the applications submitted, each vendor should be invited to the government site to meet with the team and have a 'discovery' discussion which allows the "vendors to ask questions and find answers (e.g., number and type of interfaces required and data file dimensions)" (Madden and Miranda 1998, p37). The purpose of this session is to allow the vendors the opportunity to refine the scope/cost of their proposals (Madden and Miranda, 1998). In Cork County Council a Tender Assessment Team consisting of the SEO (Finance), Head of Finance, two Accountants and two IT specialists was put in place to assess the tenders. The remit of this team was to recommend the most appropriate solution for Cork County Council. Both vendors were invited to meet the Tender Assessment Team and discuss their solutions as set out in the formal tender documents. The meetings took place on 7 June 2006 and on 12 June 2006 respectively. 
Discussions focussed on the assessment criteria set out in the tender document. Each vendor was given three hours to clarify the tender under the following headings; functionality, costs, deployment, maintenance support, vendor capacity and case studies. Both vendors were asked to provide written confirmation of areas that needed clarification during the interviews. The Tender Assessment Team was satisfied that both vendors could provide a viable Corporate Debtors solution for Cork County Council. As a result of the tender assessment the next stage was focussed on one Vendor. In particular the Team wished to verify the functionality, support and vendor capability.

\subsection{Demonstration}

The successful vendor was requested to provide a demonstration of its Corporate Debtors System. The Tender Assessment Team provided a list of twenty nine specific areas to be covered in the demonstration, under the following headings:

Raising and Managing Charges

Receipting

Reporting

Transaction Processing

Inquiry Options

The demonstration was held at the vendor's office in Dublin on 6 July 2006. This demonstration, combined with future clarification in writing, satisfied the Tender Assessment Team as to the functionality set out by the vendor in its formal tender document.

\subsection{Site Visit}

Cork County Councils team assessment members then visited another Local Authority, where the vendor already had a similar Corporate Debtors System in operation. The site visit took place on 26 July 2006 and focussed on the following areas:

How the individual modules integrate with the Corporate Debtors System

How the on-line payments module is performing (live)

The Local Authorities working relationship with the vendor

The Tender Assessment Team found that much of the system's functionality demonstrated was specifically geared to providing a solution in an Irish Local Authority environment. While there are differences in scale between the two organisations, the team was satisfied that what was demonstrated could be implemented successfully in Cork County Council. More importantly, the site visit established that Vendor capability and support arrangements were of the standard required by Cork County Council. The Local Authority had a good working relationship with the vendor and was happy with the calibre of people provided to work on the various debtors projects. The Local Authority was satisfied that the vendor was honouring all maintenance/support agreements. The Tender Assessment Team was now satisfied that the vendor capability and maintenance/support information could be confirmed.

\subsection{Awarding the Contract}

The decision was made to award the contract to this vendor. The other vendor was notified, by letter, of its unsuccessful tender application. The contract with the vendor was signed Thursday 21 September 2006. The Corporate Debtors System was up and running by mid May 2007.

\section{Conclusion}

The new Corporate Debtors System for Cork County Council was a major project. Firstly, the problem was defined. Several debtors' legacy systems were being used and these were not directly linked to the General Ledger system. This resulted in inadequate collection levels and major financial accounting difficulties at month- and year-end. Secondly, the management team identified and researched four viable alternatives. The solution they identified was one of centralising the debtors system and interfacing it with the existing General Ledger system. Thirdly, a Tender Assessment Team called tenders from potential supplier. These tenders were reviewed through a system of pre-qualification tenders, full tender documents, demonstrations and site visits. Finally, the team agreed and signed a contract with the successful vendor. These step outlined would be a good template for other public sector organisations throughout the world.

The future vision of Cork County Council is to continue this process by consolidating the multiple Debtors Legacy Systems that exist for its other services into the single Corporate Debtors System. The Corporate Debtors System described in this paper will be able to facilitate this. It is also the Council's future intention to allow the public to 
view their accounts and pay their Debtors bills online.

This descriptive nature of this research opens many new areas of further research, for example the implementation of integrated systems in other public sector organisations. Also, the role of the accountant in the implementation of integrated systems in the public sector still requires a lot more research. Future research could also be carried out on how integrated systems cope with service expansion, for example when the Corporate Debtors System in Cork County Council expands to include Rates and the Fire Service. All of these areas are worthy of further research work.

\section{References}

Botta-Genoulaz, V., and Millet, P-A (2006). An investigation into the use of ERP systems in the Service Sector. International Journal of Production Economics, 99, 2006, 202-221.

Chester, B., (2006). Best of Breed or Integrated Solution?. The AIIM E-Doc, Nov/Dec, 48-50.

Davenport, T., (1998). Putting the Enterprise into the Enterprise System" Harvard Business Review, July-August, 121-131.

Geishecker, L., (1999). ERP vs Best-of-Breed. Strategic Finance, 80.9, March, 62-66.

Global Supply Chain Conference, (2006). ERP vs. Best-of-Breed Software: How High-growth Companies Make their Decisions. Global Supply Chain Conference, www.scmr.com/gscc, January, pp G43-G45.

Griffith, L., (2000). ERP vs best-of-breed IT architecture: Is the pendulum swinging?. Apparel Industry, Vol.61, Issue 6, 72.

Holland, C., and Light, B., (1999). A Critical Success Factors Model for ERP Implementation. IEEE Software, May/June, 30-35.

Hunter, N (2005). C\&AG criticises running of PPARS. www.irishhealth.com, posted Tuesday 13 Dec 2005.

Hyvonen, T., (2003). Management Accounting and information systems: ERP versus BoB. European Accounting Review, 12:1, 155-173.

Klaus, H., Rosemann M., and Gable, G.G., (2000). What is ERP?. Information Systems Frontiers, 2 (2): 141-62.

Kumar, V., Maheshwari, B., and Kumar, U (2002). ERP systems implementations: Best Practices in Canadian government organisations. Government Information Quarterly, 19, 147-172.

Langnau, L., (2004). Integrating Systems, End to End. Material Handling Management, Sep 2004, Vol.59, Issue 9, 47-51.

Lapsley, I., and Pallot, J., (2000). Accounting, management and organisational change: A comparative study of local government. Management Accounting Research, 11, 213-229.

Lapsley, I., and Wright, E., (2004). The diffusion of management accounting innovations in the public sector: a research agenda. Management Accounting Research, 15, 355-374.

Madden. M., and Miranda, R. (1998). Contracting for enterprise financial software: the methodology of parallel negotiations. Government Finance Review, October V14.n5, 33-39.

Markus, M.L., and Tanis, C., (2000). The Enterprise System Experience: From Adoption to Success," in Framing the Domains of IT Management: Projecting the Future through the Past. Zmud R. W. (ed.) Pinnaflex Educational Resources Inc., Cincinnati, Ohio, 173-207.

Millman, G. J., (2004). What did you get from ERP and what can you get?" Financial Executive, May, 38-42.

Miranda, R (1999). The rise of ERP technology in the public sector. Government Finance Review, August, V15 i4, 9-17.

Miranda, R (2002). Needs Assessments and Business Case Analysis for Technology Investment Decisions. Government Finance Review, October, 12-16.

Miranda, R (2003). Poison Pills and White Knights, Doing Business with an ERP Industry in Transition. Government Finance Review, August, 15-25.

Miranda, R., and Kavanagh, S., (2005), 'Achieving Government Transformation through ERP systems', Government Finance Review, June, 37-42.

Moriarty, S., (1999). Breeding the best. Management Accounting (UK), 77, October, 52.

Nah, F., Zuckweiler, K. M., and Lee-Shang Lau, J., (2003). ERP Implementation: Chief Information Officers' 
Perceptions of Critical Success Factors. Journal of Human-Computer Interaction, 16, 1, 5-22.

Nah, F., and Delgado, S., (2006). Critical Success Factors for Enterprise Resource Planning Implementations and Upgrade. Journal of Computer Information Systems, Special Issue, 99-113.

Newman, M., and Westrup, C., (2005). Making ERP"s work: accountants and the introduction of ERP systems. European Journal of Information Systems, 14, 258-272.

Ramon Gil-Garcia, J., and Pardo, T.A., (2005). E - Government success factors: Mapping practical tools to theoretical foundations. Government Information Quarterly, Volume 22, 2, 187-216.

Rikhardsson, P., and Kraemmergaard, P., (2006). Identifying the impacts of enterprise system implementation and use: Examples from Denmark. International Journal of Accounting Information Systems, 7, 36-49.

Scapens, R, W., and Jazayeri, M., (2003). ERP systems and management accounting change: opportunities or impacts? A research note. European Accounting Review, 12:1, 201-233.

Notes

Note 1. Interview with Financial Accountant 26/04/2007

Note 2. Interview with SEO (Finance) 30/03/2007

Note 3. Interview with SEO (ICT) 29/03/2007

Note 4. Interview with Head of Finance 30/03/2007

Note 5. Interview with SEO (ICT) 29/03/2007

Note 6. Interview with SEO (ICT) 29/03/2007

Note 7. Interview with Financial Accountant 26/04/2007

Note 8. Interview with SEO (Finance) 6/06/2006

\section{Appendix 1: Cork County Council - Needs Assessment Time Line Chart}

\begin{tabular}{|c|c|c|c|c|c|c|c|c|c|c|}
\hline Tasks & Dec-05 & Jan-06 & Feb-06 & Mar-06 & Apr-06 & May-06 & Jun-06 & Jul-06 & Aug-06 & Sep-06 \\
\hline Define the Proble & & & & & & & & & & \\
\hline Identify \& Resea & & & & & & & & & & \\
\hline Pre-Qualilfication & & & & & & & & & & \\
\hline Tender Documer & & & & & & & & & & \\
\hline Opening of Tend & & & & & & & & & & \\
\hline Assessment of $\mathrm{T}$ & & & & & & & & & & \\
\hline Vendor Interview & & & & & & & & & & \\
\hline Demonstration & & & & & & & & & & \\
\hline Site Visit & & & & & & & & & & \\
\hline Contract Signed & & & & & & & & & & \\
\hline
\end{tabular}

